\title{
The effect of pea albumins on immune response in mice
}

\author{
DAGMARA ZŁOTKOWSKA, EWA WASILEWSKA, EWA KUBICKA, BARBARA WRÓBLEWSKA
}

Department of Food Immunology and Microbiology, Institute of Animal Reproduction and Food Research of Polish Academy of Science, Olsztyn, Poland

\begin{abstract}
The aim of presented studies was to determine the effect of total pea albumins on mice immune system response. Oral and intraperitoneal (i.p.) route of antigen administration were checked and three different adjuvants (Freund adjuvant, alum and cholera toxin) were used. All three groups showed enhancement of serum IgG and IgA antibodies production. Using cholera toxin $(C T)$ to oral immunization with pea albumins gave comparable antibodies level to intraperitoneal immunizations, and the best $T$ cell response.

Group orally immunized with pea albumins (PA) with CT as adjuvant resulted in high percentage of CD4 T cells population. We conluded, that the oral model of Balb/c mice immunization with antigen and $C T$ as adjuvant, could be used to experiments determining food proteins immunogenicity and response of effector tissue of mucosal immune system.
\end{abstract}

Key words: pea albumins, immunization, adjuvants, antibodies, CD4, CD8.

(Centr Eur J Immunol 2012; 37 (3): 232-236)

\section{Introduction}

Administration of foreign proteins - potential allergens usually affect antibodies class $\mathrm{G}$ and A production. When allergy is induced antibodies IgE have to be produced and inflammatory reactions are begining [1,2]. It is proven that the dose of allergen, as well as adjuvant used and route of administration (oral or intraperitoneal) significantly affect specific antibodies level [3]. It is also known that changing the route of immunization and dose of given allergen can shift immune response from tolerance to immunity [3]. Knowledge on those mechanisms is very important for preventing and treating food allergy. Presented paper shows difference in mice immune system response due to varied pea albumin administration. Pea albumins have been selected as they are good source of valuable nutritional compounds [4] and they are present in traditional home cooking in number of countries, for instant Poland or UK. In the times, while meat substitute was looked for, the pea was found to be the one after soya due to high nutritional value and high proteins content [5]. Pea albumins, especially fractions P1 and P2 with molecular masses of $6.5 \mathrm{kDa}$ and $26 \mathrm{kDa}$ $[6,7]$ are also considered as fractions with high allergenic potential. The aim of the presented studies was to deter- mine the effect of total pea albumins on mice immune system response, to choose between three ways of immunization the best model for checking their immunogenicity.

\section{Material and methods}

Pea (Pisum sativum) seeds of Ramrod cultivar were obtained from the Institute of Plant Farming in Łagiewniki. Seeds were milled in a WZ-1 grinder (ZBPP Sadkiewicz Instruments, Poland) and sieved through a standard $0.40 \mathrm{~mm}$ sieve (NAGEMA, Germany).

\section{Albumins extraction}

Pea flour $(50 \mathrm{~g})$ was extracted with $1000 \mathrm{ml}$ of $\mathrm{H}_{2} \mathrm{O}$ d.d. at $4^{\circ} \mathrm{C}$ for $24 \mathrm{~h}$, then the extract was centrifuged $\left(22500 \times \mathrm{g}, 4^{\circ} \mathrm{C}, 15 \mathrm{~min}\right)$. Supernatant containing total albumins was dialyzed against distilled water for $48 \mathrm{~h}$. Then, the dialysed product was lyophilized, and obtained total pea albumin powder was further referred to as the pea albumins [8].

\section{HPLC analysis}

The purity and molecular masses (MM) of isolated proteins were checked in Shimadzu HPLC System. The pro- 
teins were eluted from the Biosep SEC-S 2000 column $(75 \times 7.80 \mathrm{~mm})$ with $25 \mathrm{mM}$ phosphate buffer $\mathrm{pH} 7.0$ at flow rate of $1 \mathrm{ml} / \mathrm{min}$. The detection was performed with $\mathrm{UV}$ at 214 and $280 \mathrm{~nm}$. Molecular weight marker kit for gel filtration chromatography (MM range: 6500-66 000) was used as the molecular mass standards.

\section{Mice experiments}

Balb/c mice, 6- to 8-week old, were purchased from the Medical Research Center PAS, Warsaw. Mice were immunized with pea albumins (PA) in three ways: group I, intraperitoneally on day $0,7,14$ with $100 \mu \mathrm{g}$ of PA with $100 \mu$ l of Complete Freund's Adjuvant (FA) for first immunization and $100 \mu \mathrm{l}$ of incomplete FA for next two immunizations; group II orally with $200 \mu \mathrm{g}$ PA with $61.5 \mu$ l Alum (Sigma) by 10 consequence days and group III with $200 \mu \mathrm{g}$ PA with $5 \mu$ l Cholera Toxin (CT) for first immunization and $2.5 \mu \mathrm{l} \mathrm{CT}$ for the next, for 10 consequence days. Oral doses were administered with a 21-gauge gavage needle attached to a $1 \mathrm{ml}$ tuberculin syringe directly to the stomach. On 14, 21, 28 and 35 day from the first immunization, blood and fecal samples were collected for future $\mathrm{IgG}$ and IgA level analysis [9]. Each experimental group consists of 10 mice. The Local Care Use of Animal Committee (authorization 96/2010/N) approved animal handling and experimental procedures.

\section{Anti-PA antibodies level determination}

To evaluate PA-specific endpoint $\mathrm{Ab}$ titers in serum and fecal extracts standard ELISA method was used. Following washing, horseradish peroxidase-conjugated secondary goatanti-IgG and - IgA (Sigma) were added to the wells and incubated for $90 \mathrm{~min}$ at $37^{\circ} \mathrm{C}$. After washing, ABTS substrate (Moss) was added and incubated for $60 \mathrm{~min}$ at room temperature. Endpoint titers were defined as the highest reciprocal of dilution of sample, giving an absorbance at OD415 above 0.100 OD units above negative control [9].

\section{Lymphocyte isolation}

On day 35 mice were killed and tissue samples from spleen and mesenteric lymph nodes were collected for lym- phocytes isolation $[9,10]$. Cells at a concentration of $2 \times 10^{5}$ cell per $100 \mu \mathrm{l}$ were cultured in RPMI 1640 medium (Sigma) supplemented with $10 \%$ heat inactivated fetal bovine serum (FBS, GIBCO), $1 \%$ non-essential amino acids (Sigma) and $1 \%$ penicilin-streptomicin solution (Sigma), at $37^{\circ} \mathrm{C}$ in the atmosphere of $5 \% \mathrm{CO}$. Lymphocytes were cultured for 4 days in presence of $1 \mathrm{mg} / \mathrm{ml} \mathrm{PA}$.

\section{Flow cytometry analysis}

Spleen (SPL) and mesenteric lymph nodes (MLN) lymphocytes were stained with FITC-conjugated anti-mouse CD4 mAbs (BD Pharmingen, clone H123.19) versus phycoerythrin (PE) - conjugated anti-mouse CD8 mAb (BD Pharmingen, clone 53-6.7). Two-color Flow cytometry (FCM) analysis was performed on gated lymphocyte cells [11].

\section{Statistical analysis}

One-way ANOVA followed by a Tukey test was applied to evaluate statistical differences between antibodies titres in experimental groups. The flow cytometry data were analyzed by one-way ANOVA followed by a Holm-Sidak method. Results were considered to be statistically significant if $p$-value was less than 0.05 .

\section{Results}

Pea albumins were extracted from the flour according to the method described above. On the HPLC chromatogram of pea albumins extract (Fig. 1) there was found one main peak eluted at $2.32 \mathrm{~min}$ of chromatographic separation and corresponding to the protein of molecular mass about $12 \mathrm{kDa}$ and 3 minor peaks corresponding to the proteins of molecular masses lower than $12 \mathrm{kDa}$.

All experimental groups showed production of PA-specific immunoglobulins class G (Fig. 2). Specific IgG titer rised in group intraperitonelly immunized during the time of experiment from $2^{12} \pm 0.2$ after 14 days to $2^{15} \pm 0.6$ after 35 days. Oral PA administrations in the presence of CT as adjuvant induced specific $\operatorname{IgG}$ titer $211 \pm 0.6$. During the next 7 days titre decreased to the level about 29 and was

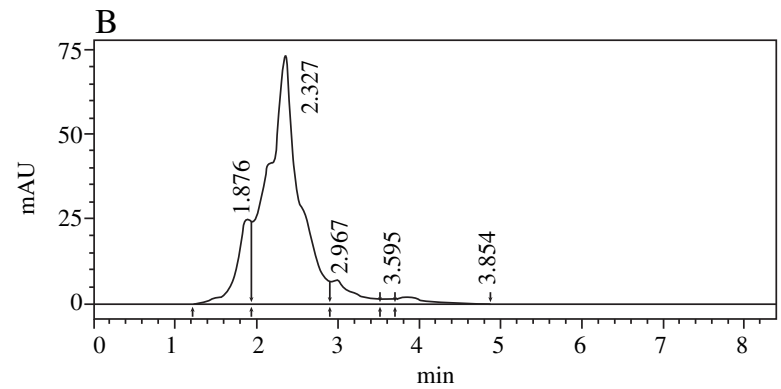

Fig. 1. HPLC analysis of pea albumins extracts (BiosepSEC-S 2000 column $75 \times 7.80 \mathrm{~mm}$ ): A - chromatogram at $214 \mathrm{~nm}$, B - chromatogram at $280 \mathrm{~nm}$ 
serum $\operatorname{IgG}$

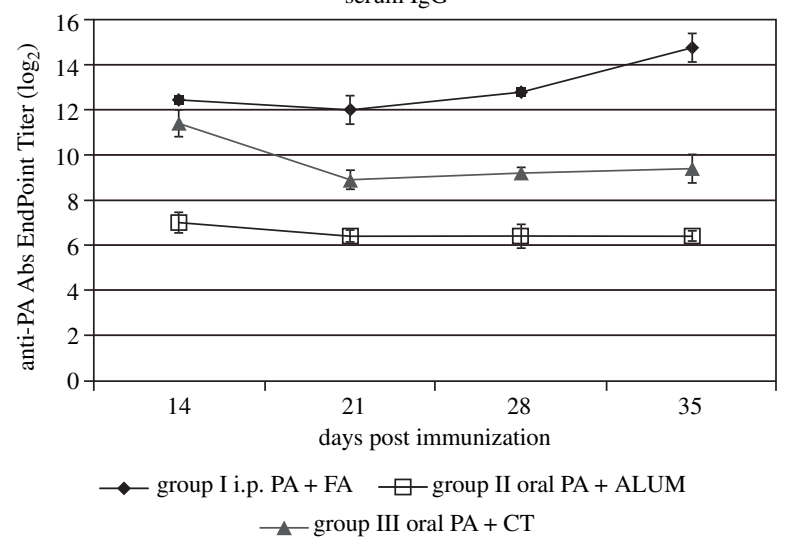

Fig. 2. Serum IgG Anti-PA antibodies EndPoint Titre after immunization with: GR I - i.p. $200 \mu \mathrm{g}$ PA with FA, GR II oral $100 \mu \mathrm{g}$ PA with Alum, GR III - oral $100 \mu \mathrm{g}$ PA with CT

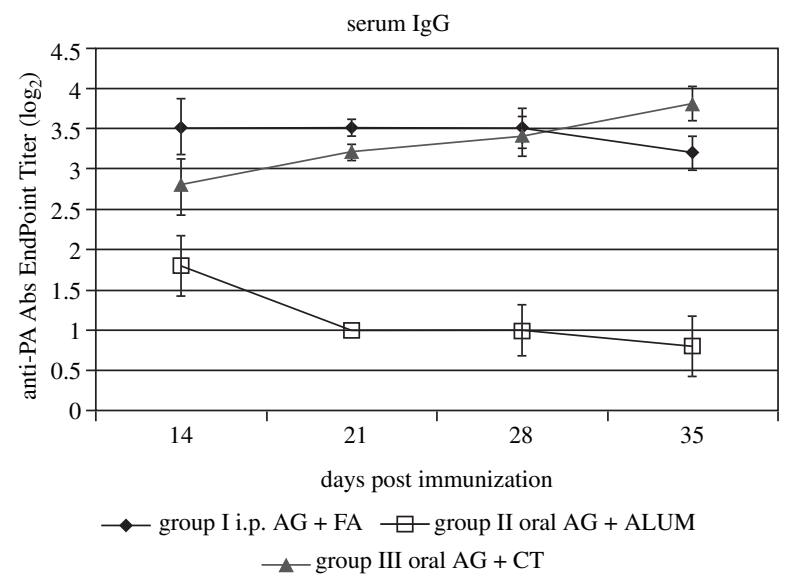

Fig. 4. Fecal IgG Anti-PA antibodies EndPoint Titre after immunization with: GR I - i.p. $200 \mu \mathrm{g}$ PA with FA, GR II oral $100 \mu \mathrm{g}$ PA with Alum, GR III - oral $100 \mu \mathrm{g}$ PA with CT

constant by the next 14 days. The lower induction of antiPA IgG (Fig. 2) and IgA (Fig. 3) was found in group immunized orally in the presence of alum as adiuvant. Interesting diferences were found in induction of specific IgA. Oral immunization with CT resulted in high titre $28 \pm 0.7$ after 14 days of experiment and remained close to that value by the next 21 days (Fig. 3). Intraperitoneal immunizations induced specific IgA on detectable level on 21 day of experiment and then the increase up to $28 \pm 0.2$ was observed by the next 14 days.

Fecal samples IgA level was low in all experimentals groups (Fig. 4). Oral immunization with alum gave statisticaly significant diferences in IgA level as compared to group I and III $(p<0.05)$.

To check CD4 and CD8 T cells distribution after different immunizations, lymphocytes from spleen and mesen-

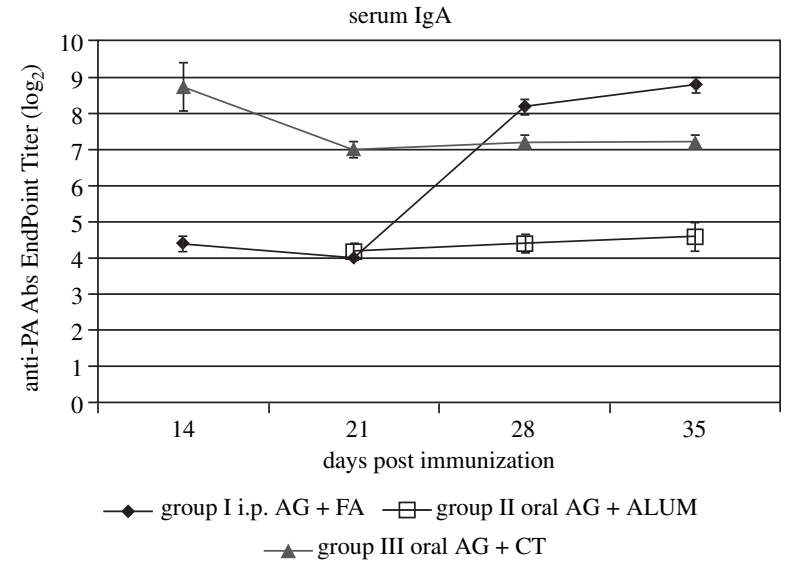

Fig. 3. Serum IgA Anti-PA antibodies EndPoint Titre after immunization with: GR I - i.p. $200 \mu \mathrm{g}$ PA with FA, GR II oral $100 \mu \mathrm{g}$ PA with Alum, GR III - oral $100 \mu \mathrm{g}$ PA with CT

teric lymph nodes (MLNs) were isolated and stained (Fig. 5). MLNs second after Payer's Patches are thought to be the main site for oral tolerance induction [12]. As results show CD4 and CD8 T cells percentage are strictly correlated with route of immunization and used adjuvant. Oral immunization gave the higher level of induced CD8 T cells in MLNs when alum was used as well as CT, 9.1 \pm 0.25 and $13 \pm 0.35$, respectively (Fig. 5C, E). Intraperitoneal immunization gave statistically different (for $\mathrm{p} \geq 0.001$ ) level of MLNs CD8, $4.9 \pm 0.26 \%$. For MLNs CD4 statistically important differences (for $p=0.04$ ) were found between oral and i.p. immunized groups (Fig. 5 A, C, D). There were no differences between using Alum or CT as adjuvant. Similar situations were found after fenotyping SPL lymphocytes (Fig. 5B, D, F). Using CT as adjuvant gave the best percentage of CD8, $7.8 \pm 0.25$ compare to i.p. group $0.7 \pm 0.01$ and group II $5.7 \pm 0.07$ ( $p \geq 0.001)$. Intraperitoneal immunization significantly increased CD4 induction in group III (Fig. 5A, B) as compared to group II and III where alum and CT were used (Fig. 5C-F) $(p \geq 0.001)$.

\section{Discussion}

Presented experiments showed that each used route of immunization gave positive results for antibodies production. High level of serum specific IgG and IgA were found in all groups. While determining secretory IgA levels, it was found that using alum for oral immunization is not enough efficient. Alum is widely used adjuvant in human vaccines [13]. It has been found to be able to suppress Th2 cytokine production locally [14] and generate specific antibody and $\mathrm{T}$ cell response $[15,16]$. In presented models, level of secretory IgA induced in group II (oral Ag+Alum) was the lowest. Using CT as adjuvant during oral immunization gave not significant differences as compared to i.p. immunization. Induction of CD4 T cells population is also the most 

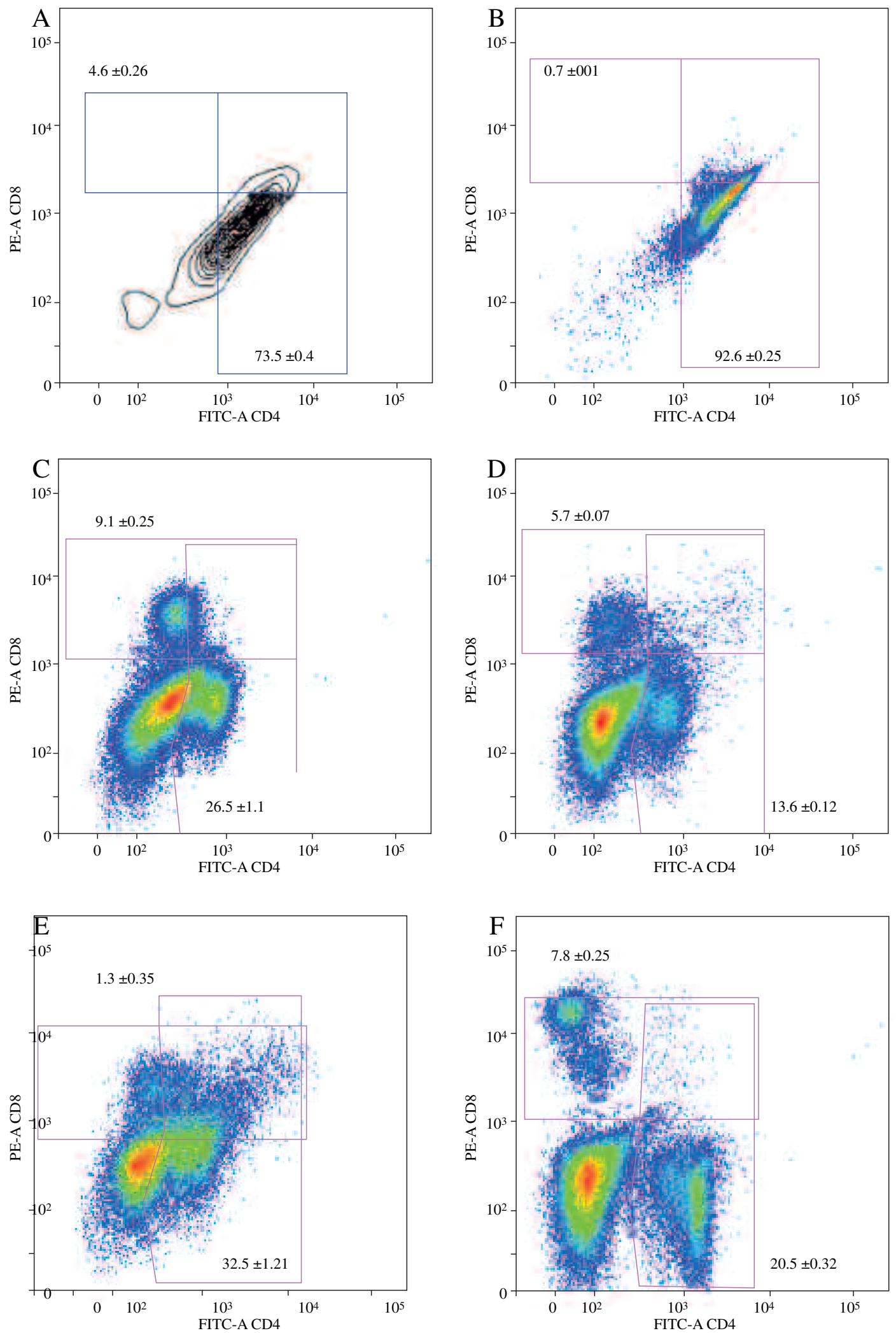

Fig. 5. CD4 and CD8 T cells distribution in MLN ans SPL lymphocytes isolated from: A, B - GR I - i.p. $200 \mu \mathrm{g}$ PA with FA; C, D - GR II - oral $100 \mu \mathrm{g}$ PA with Alum; E, F - GR III - oral $100 \mu \mathrm{g}$ PA with CT 
efficient in group III (Fig. 5E, F), however i.p. immunization are invasive and do not correlate with natural occurring food antigen absorption. There are a number of examples using mucosal adjuvant CT in OVA experiments to induce tolerance $[3,17]$ or for inducing tetanus protection [18]. It is proven that CD4 T cells are precursors of subpopulation of regulatory cells, which are able to modulate immune response, inhibit immune diseases at sites of inflammation or infection $[19,20]$. What is a very important, regulatory $\mathrm{T}$ cells have effect in the lymph nodes and in the target tissue [20], therefore it is very important to induce them during immunization.

Presented results have proven that using CT to oral immunization with pea albumins gave comparable antibodies level to intraperitoneal immunizations and the best $\mathrm{T}$ cell response.

\section{Conclusions}

Oral model of Balb/C immunization with antigen and $\mathrm{CT}$ as adiuvant can be used to experiments determining food proteins immunogenicity and their effect on effector tissue response of mucosal immune system.

This study was supported financally by the statutory fund of Department of Immunology and Food Microbiology, IAR\&FR PAS, Olsztyn, Poland.

\section{References}

1. Helm RM, Burks AW (2000): Mechanisms of food allergy. Curr Opin Immunol 12: 647-653.

2. Pałgan K, Bartuzi Z (2011): Genetic aspects of food allergy. Post Dermatol Alergol 2: 103-106.

3. Rynda A, Maddaloni M, Mierzejewska D, et al. (2008): Lowdose tolerance is mediated by the $\mathrm{M}$ cell ligand, reovirus protein s1. J Immunol 180: 5187-5200.

4. Urbano G, López-Jurando M, Frejnagel S, et al. (2005): Nutritional assessment of raw and germinated pea (Pisum sativum $L$.) protein and carbohydrate by in vitro and in vivo techniques. Nutrition 21: 230-239.

5. Davies J, Lightowler H (1998): Plant-based alternatives to meat. Nutr Food Sci 98: 90-94.

6. Sell M, Steinhart H, Paschke A (2005): Influence of maturation on the alteration of allergenicity of green pea (Pisum sativum L.). J. Agricul Food Chem 53: 1717-1722.

7. Crévieu I, Bérot S, Guéguen J (1996): Large scale procedure for fractionation of albumins and globulins from pea seeds. Nahrung 40: 237-244.

8 Higgins TJV, Chandler PM, Randall PJ, et al. (1986): Gene structure, and regulation of the synthesis of a sulfur-rich protein in pea seeds. J Biol Chem 261: 11124-11130.

9. Yamanaka H, Hoyt T, Yang X, et al. (2008): A nasal interleukin-12 DNA vaccine coexpressing Yersinia pestis F1-V fusion protein confers protection against pneumonic plague. Infec Immun 76: 4564-4573.

10. Maddaloni M, Staats HF, Mierzejewska D, et al. (2006): Mucosal vaccine targeting improves onset of mucosal and systemic immunity to botulinum neurotoxin A. A J Immunol 177: 5524-5535.
11. Holmes K, Lantz, Fowlkes BJ, Schmid I, Giorgi JV (2001): Preparation of cells and reagents for flow cytometry. In: Current protocols in immunology. John Wiley \& Sons, Inc. 5.3.15.3.24.

12. Macpherson AJ, Smith K (2006): Mesenteric lymph nodes at the center of immune anatomy. J Exp Med 203: 497-500.

13. Kool M, Fierens K, Lambrecht BN (2012): Alum adjuvant: Some of the Tricks of the oldest adjuvant. J Med Microbiol 61 (Pt 7): 927-934.

14. Minoura T, Kato S, Otsu S, et al. (2003): Childhood Helicobacter pylori infection in a murine model: maternal transmission and eradication by systemic immunization using bacterial antigen-aluminium hydroxide. Clin Exp Immunol 134 : 32-37.

15. Sijun H, Yong H (2009): Helicobacter pylori vaccine: mucosal adjuvant \& delivery systems. Indian J Med Res 130: 115124.

16. Kool M, Pétrilli V, De Smedt T, et al. (2008): Cutting edge: alum adjuvant stimulates inflammatory dendritic cells through activation of the NALP3 inflammasome. J Immunol 181: 3755 3759.

17. Sun J-B, Raghavan S, Sjöling A, et al. (2006): Oral tolerance induction with antigen conjugated to cholera toxin B subunit generates both Foxp3+CD25+ and Foxp3-CD25- CD4+ regulatory T cells. J Immunol 177: 7634-7644.

18. Isaka M, Yasuda Y, Kozuka S, et al. (1998): Systemic and mucosal immune responses of mice to aluminium-adsorbed or aluminium-non-adsorbed tetanus toxoid administered intranasally with recombinant cholera toxin B subunit. Vaccine 16 : 1620-1626.

19. Chen X, Oppenheim JJ, Howard OMZ (2005): BALB/c mice have more $\mathrm{CD} 4+\mathrm{CD} 25+\mathrm{T}$ regulatory cells and show greater susceptibility to suppression of their CD4+CD25- responder $\mathrm{T}$ cells than C57BL/6 mice. J. Leukoc Biol 78: 114-121.

20. Belkaid Y, Tarbell KV (2009): Arming Treg Cells at the Inflammatory Site Immunity 30: 322-323. 